\title{
Prevalence and Distribution of the Third Coronary Artery in Kenyans
}

\author{
Prevalencia y Distribución de la Tercera Arteria Coronaria en Kenianos
}

Olabu, B. O.; Saidi H. S.; Hassanali, J. \& Ogeng'o J. A.

OLABU, B. O.; SAIDI, H. S.; HASSANALI, J. \& OGENG'O, J. A. Prevalence and distribution of the third coronary artery in kenyans. Int. J.Morphol., 25(4):851-854, 2007.

SUMMARY: A third coronary artery (TCA) has been defined as a direct branch from the right aortic sinus (RAS) that contributes to the vascularization of the infundibulum of the right ventricle (RV). The distribution of this artery may be important in surgical procedures and in understanding the extent and progression of acute myocardial infarction. Its reported prevalence however shows ethnic disparity. The aim of the study was describe the prevalence and distribution of the third coronary artery in a Kenyan population. 148 cadaveric and postmortem human adult hearts obtained from the Department of Human Anatomy, University of Nairobi, and the Chiromo and Nairobi city mortuaries were used after an ethical approval. The hearts were studied by gross dissection for the prevalence and topographical anatomy of the TCA. Data was coded and analyzed using SPSS. The TCA is present in $35.1 \%$ of the heart specimens. It was variably distributed to the conducting system (23\%), anterior wall of the RV (100\%), interventricular septum (IVS) (51.9\%) and the apex of the heart $(5.8 \%)$. The TCA, with substantial contribution to cardiac vascularization, may be present in about a third of the Kenyans. It may constitute a significant collateral circulation to apical and septal perfusion. Interpretation of signs and symptoms of coronary occlusion should therefore consider possible contribution of this vascular channel.

KEY WORDS: Third coronary artery; Prevalence; Distribution; Kenyans.

\section{INTRODUCTION}

The third coronary artery (TCA), first described by Schlesinger et al. (1949), is a direct branch from the right aortic sinus (RAS) without any observable common trunk with the right coronary artery (RCA). It supplies the infundibulum (conu) of the RV (Schlesinger et al.; Williams et al., 1995; Vilallonga, 2003), which is usually vascularized by the conal branches of both the RCA and the left anterior descending (LAD) (Williams et al.; Vilallonga). The reported prevalence of the TCA suggests ethnic variability (Schlesinger et al.; Miyazaki \& Kato, 1988; Ivan \& Milica, 2004). Although its distribution is relatively unexplored, this artery may supply variable parts of the anterior wall of the RV and the IVS (Sahni \& Jit, 1990; Ben-Gal. et al., 1997; von Ludinghausen \& Ohmachi, 2001). There are indeed reports that electrocardiographic (ECG) evaluation in diagnosis of LAD occlusion, may not detect any ischaemic change in these regions of collateral flow (Ben-Gal. et al.; Zafrir et al., 2004). The distribution of this artery may therefore be important in the progress and extent of myocardial infarction and in cardiac surgery. Data on its prevalence and distribution is however lacking in Kenya. This study describes its prevalence, pattern of branching, distribution and extent in a Kenyan population.

\section{MATERIAL AND METHOD}

One hundred and forty eight human adult hearts from both sexes ( 82 male and 66 female) with an age range between 18 and 55 years old, were used in this study after an ethical approval from the Kenyatta National Hospital Ethical Review Committee. These were obtained from the cadavers in the Department of Human Anatomy, University of Nairobi and postmortem materials from Chiromo and Nairobi city mortuaries. Specimens with observable cardiac defects were excluded from the study. 
The hearts were dissected to display the origins of the right, left and third coronary arteries. The aortic root was split postreriorly to enable a clear view of the RAS with its orifices. With the aid of dissecting lenses, the branches of the TCA were displayed and traced distally to confirm the course, branching and termination. Photographs were taken using a digital camera (Sony Cybershot ${ }^{\circledR}$ P200, 7.2Megapixels). Data was coded, tabulated and analyzed using a computer software; statistical package of social sciences (SPSS).

\section{RESULTS}

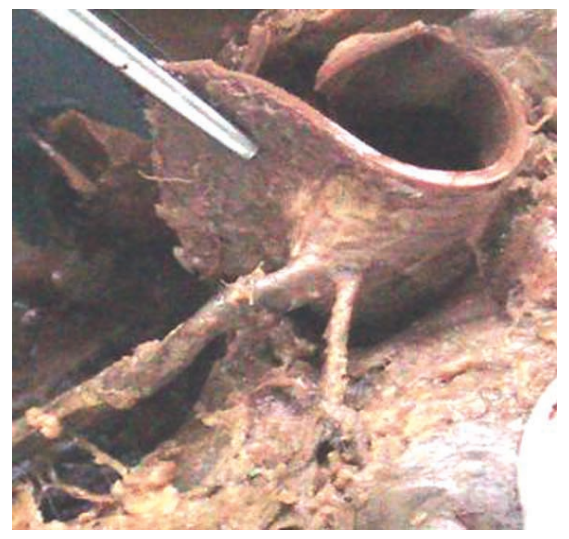

Fig. 1a. Photograph showing the RCA (1) and a TCA (2) originating from the ascending aorta.

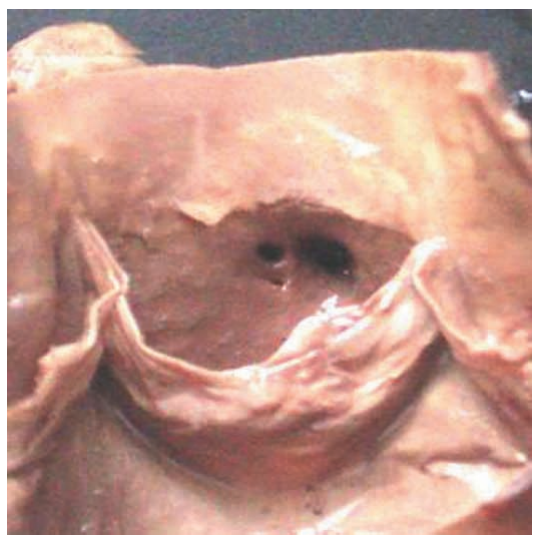

Fig. 1b. Photograph of the RAS of the heart in from inside showing three orifices for: TCA (arrowed); RCA and AVN artery.
Prevalence. The TCA was present in 52 hearts $(35.1 \%)$. The difference in prevalence between males and females was not statistically significant $(35.4 \%$ and $34.8 \%$, respectively; $\mathrm{p}=0.51)$. These TCAs originated either from two orifices ( 2 cases), single orifice separate from that of the RCA (26 cases) or from a common orifice with the RCA (24 cases) (Figs. 1a and $1 \mathrm{~b}$ ). All the RASs studied had an orifice for the RCA except one where the artery came from the left aortic sinus (LAS).

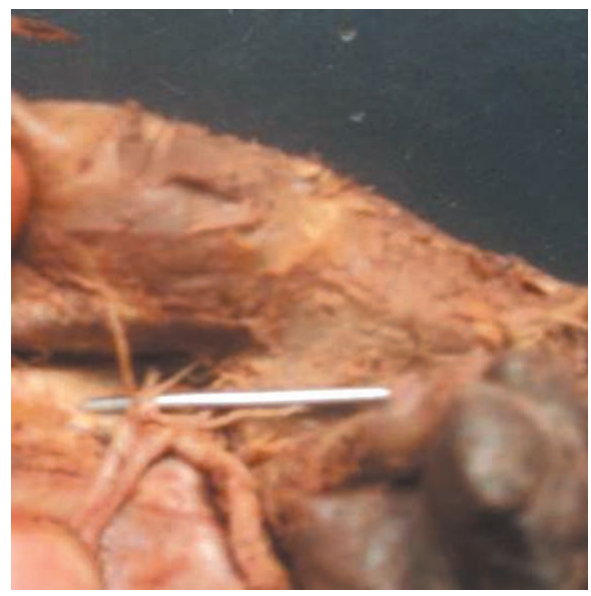

Fig. 2. Photograph of the aortic root showing the distribution of the proximal branches of the TCA (arrowed) towards the conducting system.

Course, distribution and termination. Most of the TCAs were epicardial in their entire length but three had myocardial bridges. There was a mode of three (26 cases) and a range of 0 -6 branches from the parent artery. The proximal branches vascularized the anterior wall of the RV in most cases but in 12 hearts these branches were distributed towards the region of the conducting system (Fig 2). The artery terminated as a single trunk in 29 cases while other modes of termination involved trifurcation and bifurcation in 6 and 17 cases, respectively.
The terminal branches reached the IVS in 27 cases, anterior wall of the RV in 22 cases and the apex of the heart in 3 cases. One out of these three reaching the apex formed a cruciate anastomosis with the LAD and the PIV artery (Figs. $3 a$ and $3 b$ ). Another TCA reaching the apex of the heart was larger than the RCA (Fig. 4).
Fig. 4. Photograph of the heart showing a larger TCA than the RCA.

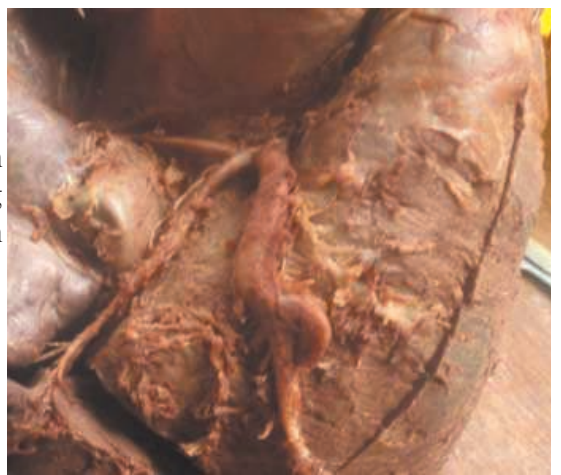




\section{DISCUSSION}

Prevalence of the third coronary artery. The present study has revealed a prevalence of $35.1 \%$ of the TCA. Other dissection studies have reported various incidences as shown in Table I.

Table I. Prevalence of the TCA in various populations.

\begin{tabular}{llc}
\hline Author & Population & Incidence \\
\hline Miyazaki \& Kato, 1988 & Japanese & $36.8 \%$ \\
Ivan \& Mi lica, 2004 & Bulgari ans & $34.8 \%$ \\
von Ludinghausen \& Ohmachi, 2001 & Germans & $7.1 \%$ \\
Kurji a et al., 1986 & Iraqui & $8 \%$ \\
Kalpana, 2003 & Indians & $24 \%$ \\
Turner \& Navaratnam, 1996 & English & $15.8 \%$ \\
\hline
\end{tabular}

It is remarkable that although the Kenyan prevalence is close to most studies, much lower values have also been reported. These findings suggest ethnic variability and appear to support the proposal by Garg et al. (2000) that there are geographical differences in coronary artery variations, which may have a genetic basis.

The differences in prevalence may also be related with age of the study population. According to Miyazaki \& Kato, the TCA may develop after birth. These workers observed that pathological hearts had a higher incidence of multiple orifices in addition to their wider ostia. They also reported a higher prevalence of the TCA in adult hearts than in fetal hearts. This view is however, at variance with that of Reinecke \& Hort (1992). These workers observed no or only unremarkable new development of coronary artery during physiological growth.

Type of TCA origin. Three types of origin were noted in the present study depending on the number of orifices: $1^{\circ}$ common orifice with the RCA; $2^{\circ}$ Single orifice separate from that of the RCA; and $3^{\circ}$ two (multiple) orifices. Two orifices within the RAS had also been reported in the same setting (Saidi et al., 2002). The separate orifices for the TCA and the RCA had been explained by insufficient unification of these two vessels, during their growth towards the ascending aorta (Reese et al., 2002; Wada et al., 2003).

Branches, course and distribution of the third coronary artery. Observations of the present study have revealed that the TCA gives 3 branches in $50 \%$ of the cases. Previous studies have however reported 2-7 with a mode of 2 branches (Iva \& Milica). Although single trunk termination was the more prevalent observation in the present study,
Ivan and Milica documented $100 \%$ terminal bifurcation of the TCA. These branches do open up in some cardiac pathologies to provide collateral perfusion. They have been shown to improve with age (Tayebjee et al., 2004).

Most of the proximal branches of the TCA were distributed to the anterior wall of the RV. This is consistent with what has been described by earlier workers Williams et al.; Ivan \& Milica; Ben-Gal et al.; Ludinghausen et al., 2003). In $23.1 \%$ of the hearts in the present study the proximal segment of the TCA sent branches to the conducting system. Although such branches of the TCA have not been explicitly described before, studies have reported an "arteria anastomotica auricularis magna" or the "Kugel's artery" arising from either the proximal RCA or LCX to the conducting system. It anastomoses with the AVN artery and occasionally, the SNA (Williams et al.; Abuin \& Nieponice, 1998; Nerantzis et al., 2004). It is possible from the course taken by the branches of the TCA in the present study that they supply the conducting system. This supports and extends the finding by Ovcina et al., (2002) that there is an extensive source of blood supply the AV segment.

A further observation of the present study is that in $51.9 \%$ of cases the TCA contributes to the supply of the IVS. Previous studies demonstrated a similar pattern (von Ludinghausen \& Ohmachi; Zafrir et al.). This may contribute to collateral circulation to the IVS during LAD occlusions hence protecting the septum. The clinical implication of this is that diagnostic tests carried out for the LAD occlusions may fail to detect any ischaemic change in this region hence giving a false better report (Zafrir et al.; Kalpana).

A hitherto undescribed observation of the present study is that the TCA may extend epicardially to supply the apex of the heart. Caution should therefore be taken during surgical procedures around the anterior wall of the $\mathrm{RV}$ and infundibulum since such a long TCA may present a surgical hazard and especially when large.

\section{CONCLUSION}

The prevalence and distribution of the TCA among Kenyans resembles that described previously in some populations. Its distribution to the conducting system, anterior wall of the RV, IVS and apex of the heart suggests that it may also constitute a significant source of collateral circulation these regions. This may be important in the interpretation of signs and symptoms of coronary artery occlusion. 
OLABU, B. O.; SAIDI, H. S.; HASSANALI, J. \& OGENG'O, J.A. Prevalencia y distribución de la tercera arteria coronaria en kenianos. Int. J. Morphol., 25(4):851-854, 2007.

RESUMEN: La tercera arteria coronaria (TCA) ha sido definida como una rama directa del seno aórtico derecho (RAS) y contribuye a la vascularización del cono arterioso del ventrículo derecho (RV). La distribución de esta arteria puede ser importante en los procedimientos quirúrgicos y para comprender la magnitud y progresión del infarto agudo del miocardio. El reporte de su prevalencia, sin embargo, muestra disparidad étnica. Se describen la prevalencia y distribución de la tercera arteria coronaria en la población keniana, en un estudio transversal. Se utilizaron 148 corazones de cadáveres adultos, obtenidos del Departamento de Anatomía de la Universidad de Nairobi y de las morgues, de las ciudades de Chiromo y Nairobi, luego de su aprobación ética. Se estudiaron en los corazones por medio de la disección macroscópica, la anatomía topográfica de la TCA y su prevalencia. Los datos fueron codificados y analizados utilizando el software SPSS. La TCA estuvo presente en el 35,1\% de los corazones. Su distribución variable fue del 23\% en el sistema de conducción cardíaco, un $100 \%$ en la pared anterior del ventrículo derecho, 51,9\% en el septo interventricular (IVS) y en el ápex del corazón un 5,8\%. La tercera arteria coronaria contribuye sustancialmente a la vascularización cardiaca y puede estar presente en cerca de un tercio de los kenianos. Esto puede constituir una significativa circulación colateral para la perfusiones apical y septal. En la interpretación de signos y síntomas de oclusión coronaria se puede considerar la posible contribución de este vaso.

PALABRAS CLAVE: Tercera arteria coronaria; Prevalencia; Distribución; Kenianos.

\section{REFERENCES}

Abuin. G. \& Nieponice, A. New findings on the origin of the blood supply to the atrioventricular node. Clinical and surgical significance. Tex. Heart Inst. J., 25(2):113-7, 1998.

Ben-Gal, T.; Sclarovsky, S; Herz, I.; Strasberg, B.; Zlotikamien, B. \& Sulkes, J. Importance of the conal branch of the right coronary artery in patients with acute myocardial infarction; electrocardiographic and angiographic correlation. J. Am. Coll. Cardiology., 29(3):506-11, 1997.

Garg, N.; Tewari, S.; Kapoor, A.; Gupta, D. K. \& Sinha, N. Primary congenital anomalies of the coronary arteries: A coronary: Arteriographic study. Int. J. Cardiol., 74(1):39-46, 2000.

Ivan, S. \& Milica, J. Morphometric characteristics of the conal coronary artery. M. J.M., 8: 2-6; 2004.

Kalpana, R. A Study on principal branches of coronary artery in humans. $J$. Anat. Soc. India, 52(2):137-40, 2003.

Kurjia, H.Z.; Cheudhry, M. S. \& Olson, T. R. Coronary artery variation in native Iraqui Population. Cathet Cardiovasc. Design., 12(60): 386-90; 1986.

Ludinghausen, M.; Hayakawa, M. \& Uzel, M. Arterial supply of and arterial predominance in the human interventricular septum. Eur. J.Anat., 7(2):101$15,2003$.

Miyazaki, M. \& Kato, M. Third coronary artery: Its development and function. Acta Cardiol., 43(4):449-57; 1988.

Nerantzis, C.E.; Marianou, S. K.; Koulouris, S. N.; Agapitos, E. B.; Papaioannou, J. A. \& Vlahos, L. J. Kugel's artery: an anatomical and angiographic study using a new technique. Tex Heart Inst. J., 31(3):267-70, 2004.

Ovcina, F.; Susko, I. \& Hasanovic, A. Intramural blood vessels in the AV segment of the human heart conduction system. Med.Arh., 56(5-6):251-3, 2002.

Reese, D. E.; Mikawa, T. \& Bader, D. M. Development of the coronary vessel system. Circ. Res., 91(9): 761-8, 2002.

Reinecke, P. \& Hort, W. The growth of coronary artery branches in man under physiological conditions. Morphological studies of corrosion casts of the anterior interventricular branch of the coronary artery. Z. Kardiol., 81(2):110$5 ; 1992$.
Sahni, D. \& Jit, I. Blood supply of the human interventricular septum in Northwest Indians. Indian Heart J., 45(5):334, 1990.

Saidi, H. S.; Olumbe, O. K. \& Kalebi, A. Anatomy and pathology of coronary artery in adult black kenyan. East Afr. Med. J., 79(6):323-7, 2002.

Schlesinger, M. J.; Olla, P. M. \& Essler, W. The conus artery: Third coronary artery. Am. Heart J., 38:823-36, 1949.

Tayebjee, M. H.; Lip, G. Y. H.; MacFadyen, R. J. Collateralization and response to obstruction of epicardial coronary artery. Q.J.Med., 97(5):259-72, 2004.

Turner, K. \& Navaratnam, V. The positions of coronary arterial ostia. Clin. Anat., 9(6): 376-80, 1996

Vilallonga, J. R. Anatomical variations of coronary arteries: I. Most frequent variations. Eur. J. Anat., 7(1): 29-41; 2003.

von Ludinghausen, M. \& Ohmachi, N. Right superior septal artery with "normal" right coronary and ectopic "early" aortic origin: a contribution to the vascular supply of the interventricular septum of the human heart. Clin. Anat.14(5): 312-9, 2001.

Wada, A. M.; Willet, S. G. \& Bader, D. Coronary vessel development: a unique form of vasculogenesis. Arterioscler. Thromb. Vasc. Biol., 23(12): 2138-45, 2003.

Williams, P. L.; Warwick, R.; Dyson, M. \& Bannister, H. et al. Cardiovascular System. Gray's Anatomy. 38 ${ }^{\text {th }}$ Ed. Churchill Livingston, London, 1995. pp1451-626.

Zafrir, B.; Zafrir, N.; Gal, T. B.; Adler, Y.; iakobishvili, Z.; Rahman, M. A. \& Birnbaum, Y. Correlation between ST elevation and Q waves on the predischarge electrocardiogram and the extent and location of MIBI perfusion defects in anterior myocardial infarction. Ann. Noninvasive Electrocardiol., 9(2):101-12; 2004.

\section{Correspondence to:}

Dr. Saidi Hassan

Department of Human Anatomy

University of Nairobi

P. O. Box 30197 - 00100 GPO

Nairobi - KENYA

Email: hsaid2ke@yahoo.com
Received: 06-07-2007 Accepted: 04-10-2007 